\title{
Anomalies in the Animal World
}

\author{
Flying Mammals; Flightless Birds and Other Curious Forms
}

By B. W. Shufeldt, M. D.

INTRODUCTION.

Biological science presents us with no question for discussion that carries with it a greater amount of interest than the one having reference to what constitutes an abnormality, or even an anomaly, in nature. By nature is meant the existing life of the animal and vegetable kingdoms as we flnd it in the world at the present time.

Many use the terms "abnormal" and "anomalous" as though they were synonymous ones, and to this some lexicons form no exception. As a matter of fact, an "abnormality" and an "anomaly" in the case of any animal or plant, may mean, and usually do, essentially two quite different things or conditions. To fix exactly what is meant by any living thing being abnormal, it is obvious that we know what constitutes, in all particulars, the normal in the case of the form to which the term is applied. Again, a character or a condition may, at the same time, be both abnormal and anomalous, the two being frequently associated.

If we select, by way of illustration, an example from our own species, it may be said that a normal man is an individual whose system and organization is completely free of disease in all particulars; who presents the average proportions with respect to figure and height; the organs of whose body are performing, at all times, their natural and particular functions; whose appendicular structures are present in due amount, number and proportions, as the teeth, the nails, the hair, and the rest. All the senses, as sight, hearing, touch, taste, and so on, are perfect, and this state also exists with respect to the mental and psychical functions of his organization; indeed, this man must, in all particulars, be the ideal perfect being, in order to meet what is implied by the term normal. So rare is this state that there are those who contend it is never to be found in nature; and certain conditions which are generally regarded as abnormal are, as a matter of fact, normal. For example, how often do we meet with men past fifty years of age possessing a perfect set of teeth? So some physicians contend that caries of the teeth is a mere evidence, among many others, indicative of advancing age in man, and to have a sound set of teeth at that time of life is an abnormal condition. Many similar instances of this, with respect to other structures, might be cited.

But to be born with teeth, or to have the heart on the right side instead of on the left, or ligatured twins (Siamese) are, with hundreds of other states, all abnormal conditions, and all, it may be said, anomalous as well. The anomalies in nature refer more particularly to the unusual or to what does not commonly occur. We find a flightless cormorant, for example, and it cannot fly for the reason that its wings have aborted. Now this is an anomalous condition, for it is by no means usual; but it is not, strictly speaking, abnormal, for the reason that what led to this bird losing its power of flight was perfectly normal in nature, and consequently the result was normal. New species, genera and families in nature are produced by certain environmental changes or by various other causes and achievements, all being entirely normal in nature, and as a consequence the resultants are normal. So we have such a bird as Harris' Cormorant placed in a new genus and given a specific namè. The same would have happened had a new species of bird with perfect fight been discovered. It is not anomalous for a bird to gradually lose its power of flight through a number of generations of descendants, and it is quite normal that it so happens under certain conditions. The ancestors of the Great Auk were undoubtedly birds of flight but flight was not especially useful to the species or even essential. Therefore it was gradually and normally lost in the descendants.

Many unthinking people speak of the anomalous or the abnormal in nature as "freak forms," but there are none such, and it is merely a term to veil their ignorance as to the causes for such departures from the usual and the normal.

Endless, Indeed, are the instances in nature of the abnormal and the anomalous, the mere naming of which would furnish material for a library of no mean proportions. Instances enough have been cited here for present purposes-enough, it is hoped, to make the distinction clear.

Mankind presents, in all parts of the world and in

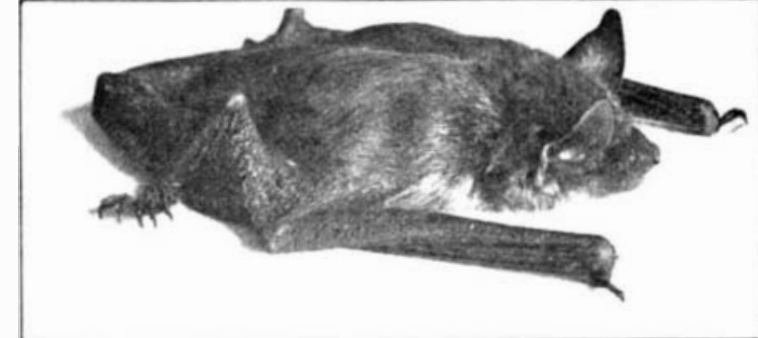

Fig. 1.-Brown bat (Eptesicus fuscus, male), of the Eastern United States, in the act of crawling on the level surface.

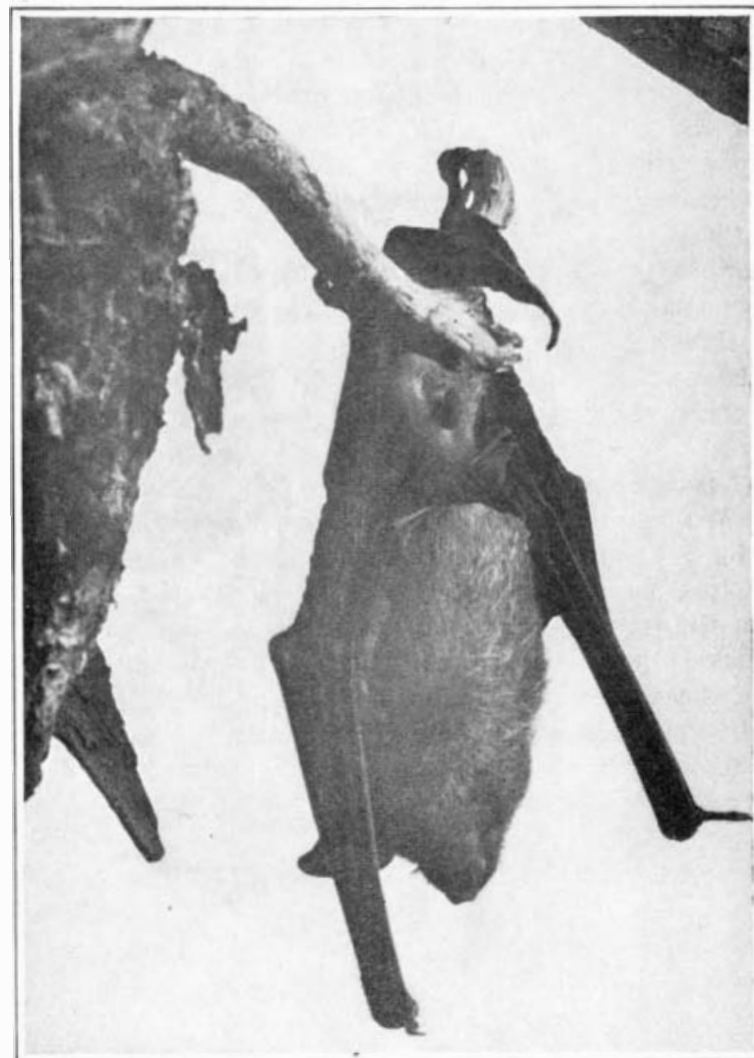

Fig. 2.-Brown bat hanging by hind feet from broken limb; same animal as in Fig. 1.

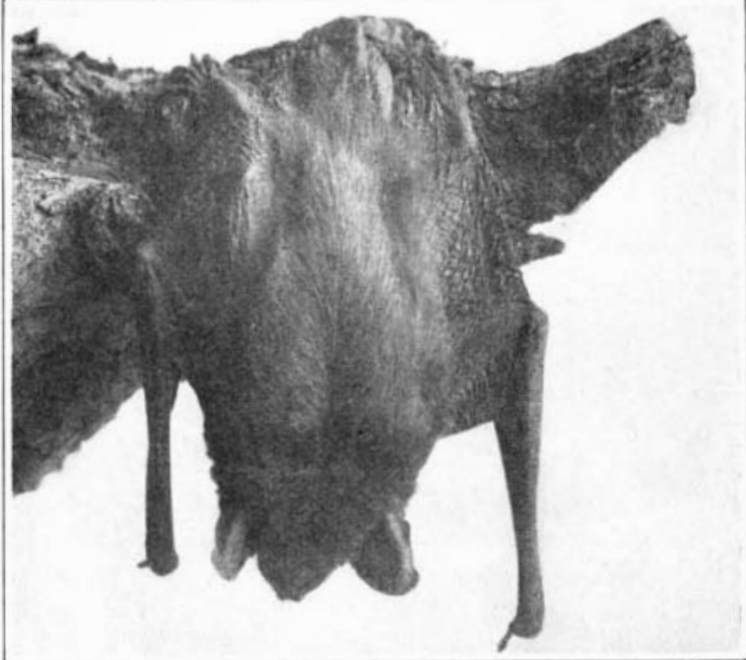

Fig. 3.-Back view of brown bat suspended from stump; same specimen as in Figs. 1 and 2. Two-thirds natural size.

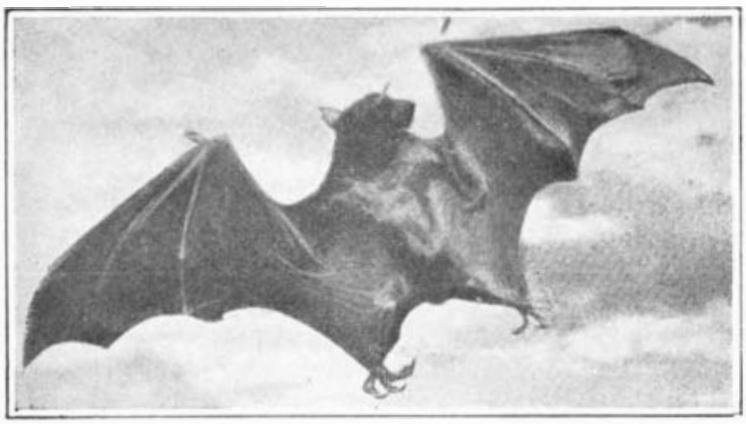

Fig. 4.- -Flying Fox" of Australia. Much reduced. all planes of society, as many and as striking abnormalities and anomalies as any other assemblage of forms in existence. The departures from the normal and the usual in men, women and children are quite similar in character to what we find among other animals, and, if anything, they are even more frequent. History furnishes many examples of people who have been more hairy than chimpanzees, and still others with far less intelligence than those simians. There have been no end of human giants and dwarfs among the various races of the earth, while albinoes occur quite as often among us as among other creatures. This is equally true with respect to polydactylous hands and feet, aborted limbs, ligatured twins, teratological specimens, and so on to the end of the category. With respect to his mentality, man exhibits a far greater number of departures from the normal in his psychoses and neuroses than all the rest of the animal world combined.

Most mammals are terrestrial or arboreal by nature and bring forth and rear their young in a manner well known to any intelligent reader. Wide departures from this rule constitute anomalies, and they are not far to seek. Such marine mammals as whales, porpoises and their congeners are familiar examples, while such animals as the dugong and the manatees furnish us with still others. Egg-laying mammals, however, and those that can fly far better than many birds so endowed, and those possessing a protective armor, are the most extraordinary species, and these are more or less fully described in this series of articles.

For similar reasons, flightless birds, one of the most pronounced anomalies in this group, have been selected for description rather than those exhibiting any other known peculiarities, of which there are by no means a paucity.

As we leave birds to pass to the reptiles and batrachians, and from them to fishes, into the unlimited host composing the great world of the invertebrata below them, of which alone over 390,000 different kind of insects are already known, it becomes more and more difficult-in the different groups as we descend the scale-to define, in any one of them, what may really be considered to be normal, ordinary or usual. It would require several volumes to do even scant justice to such a rich field for research.

There is a tremendous gap between the common perch -which may be taken as a type of the most ordinary fish-and many of the extraordinary species we have taken from the great depths of the ocean-sometimes well on to a mile below the surface. And so might be presented similar illustrations from the other great classes of animals.

For our present purpose it has been found necessary to select only some of the least known and most remarkable anomalies among a restricted few of the remaining roups to be noticed. It is hoped, however, that such as these are, they will be found both interesting and instructive, and perhaps calculated to inspire furthe research on the part of the reader, either in the libraries or, what is far better, in actual observation in the realm of nature.

It will not be necessary to acknowledge here drawings or other assistance, as this will be done very fully in the proper places in the articles. It has been one of my objects to set forth how far-reaching the interest $\mathrm{n}$ this subject has been among the world's naturalists; while, upon the other hand, it is believed that these articles as a whole will be found to be, to a large degree, sui generis.

BATS. MAMMALS POSSESSING THE POWER OF FLIGHT IN

HE HIGHEST DEGREE. VARIOUS KINDS OF BATS, WITH OBSERVATIONS ON THEIR HABITS.

When it is desired to characterize unusual power in the matter of aerial locomotion, how frequently do we aear the comparison made that it-whatever the thing ir creature may be-"flies like a bird," or it did or can fly like a bird, and so on. Such expressions occur in various languages all over the world, and it is almost a universal notion to consider birds as being ne plus ultra in this question of flight.

Whoever thinks of comparing any of our "flying" devices, or any animal not bird, with such volant capacity as the bats possess, making such comparisons with the intent of conveying superiority in the achievement? No one. When we come to really think seriously about this flight of birds, some curious facts assert them- 
selves with great force and promptness. In the first place, we have, in various parts of the world and representing divers families of birds, some that cannot fly at all, such, for example, as ostriches, kiwis, and their congeners; others possess but very limited powers of flight, as certain species of parrots, rails, and others. Now a teal duck can fly with extraordinary power and rapidity, for it has been estimated that it can thus proceed at the rate of between eighty and ninety miles per hour. However, for the most part it is like the flight of a bullet and with no more variation to it. Variation only occurs occasionally and chiefly at the stages of commencing and terminating its flight.

A perfect host of all sorts of species of birds in the world are very indifferent fliers, and they accomplish their migrations sometimes through a species of feeble flight, in no way associated with the idea of power or variety. Most of the flight of our aeroplanes is after the order of some of the swift-flying ducks, or the sailing flight of various partridges, quails, or their kind.

Humming-birds, which are, by the way, conflned to

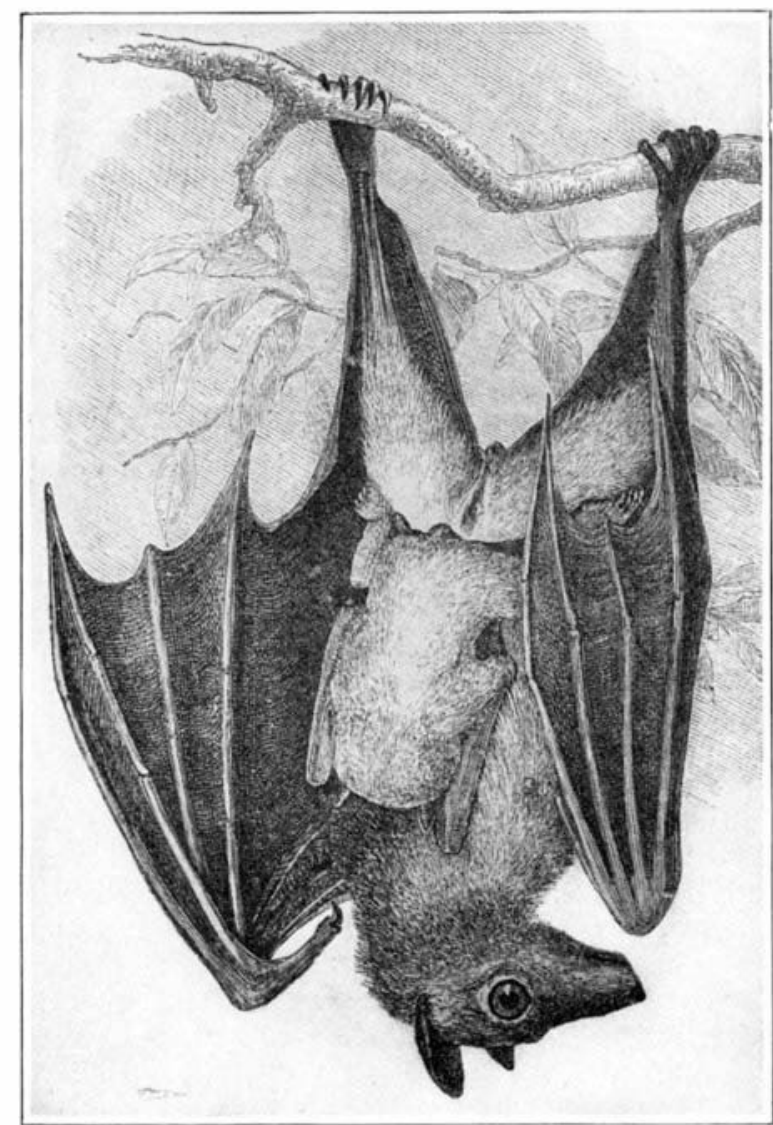

Fig. 6.-South African collared fruit bat and young (Cynonycteris collaris); female.

Much reduced. Photo by the author of Fig. 13 of "List of Animals," Zoölogical Society, London, 1896. See also P.
Z. S., 1870 , p. 127.

the Western Hemisphere, perhaps stand among the most powerful fliers of the world's existing avifauna; moreover, their flight is extremely varied and characteristic of the group, being entirely different from that of the birds we call swifts-a family with which the vast majority of present-day ornithologists associate them.

So much for bird-flight; and with due consideration for all of its varied kinds, there is no single bird, apart from its possessing great power of flight in a straight line or in a more or less curved one, that can, in any way, compare with the remarkable flying accomplishments of any of the smaller bats of the world or, presumably, with the big ones either.

Take our common little Brown bat of the Eastern United States, for example (Figs. 1 to 3 ); there is no bird of its size that can possibly equal it with respect to its performances in the air. To be sure, the best of these are to be observed during the hour of twilight; sometimes during moonlit nights, or even at early dawn. This is not to be taken into consideration, however, for the animal is a nocturnal one by habit, although there are times when it may be seen abroad during the very middle of the day, with the sun shining at its best; this is a rare occurrence, however.

Our brown bat cannot fly with the rapidity or the power of a teal duck, though it may, under proper conditions, sustain a flight which for swiftness is quite coequal with that of any of the medium-sized passerine birds, such, for example, as robins or marsh blackbirds. To study the capacity of one of these aerial acrobats at its best is to observe the volant gymnastics it performs when in quest of its evening meal, which it finds in the host of nocturnal insects, as these maneuver meaninglessly in the glare of a street arc-light. No

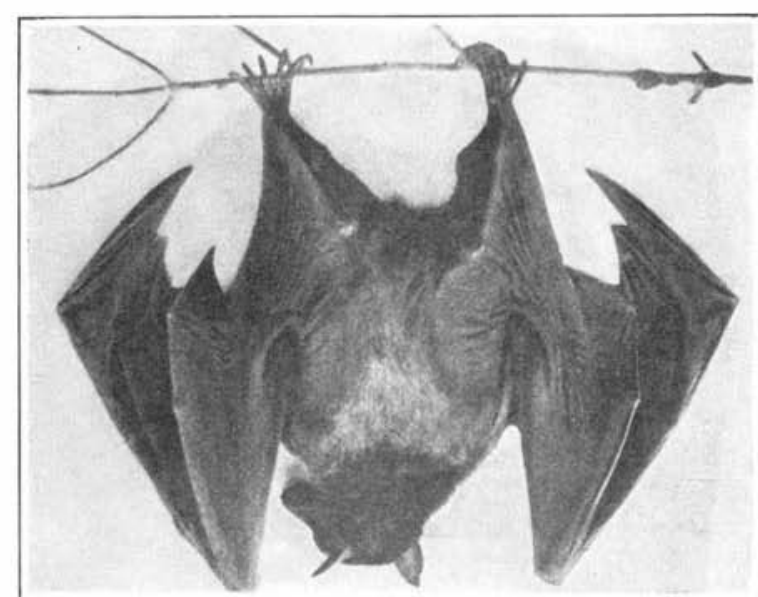

Fig. 5.-Australian fruit bat or "Flying Fox." Usual way of suspending itself when at rest.

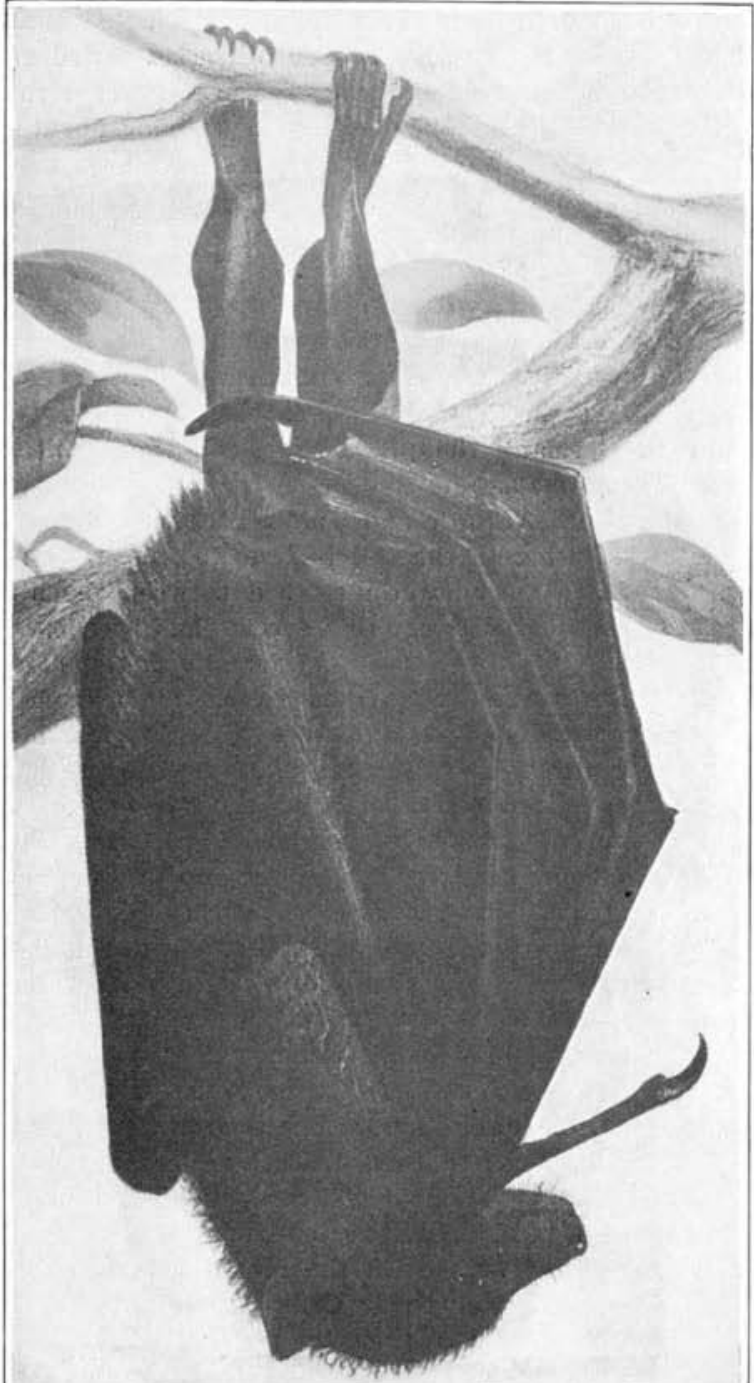

Fig. 7.-Thomas's fruit bat (Pteropus notalis); female; from Christmas Island.

Photo by the author of colored plate XLI, P. Z. S., 1887, p. 511. A large, almost black species.

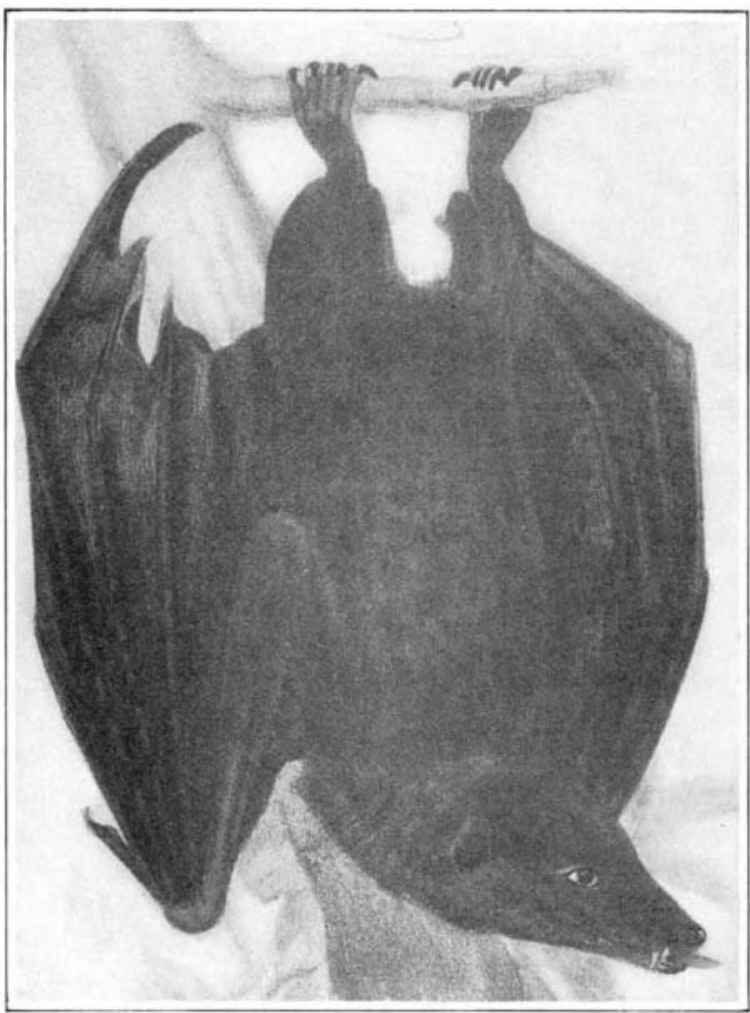

Fig. 9.-Woodford's fruit bat (Nesonycteris woodfordi), from Fauro Island.

Body fulvous-yellow, wings black. Photo by the author of plate xxvi, P. Z. S., 1887 bird living can, in flight, in any way equal its movements upon such occasions; in its efforts to seize its prey, this little winged entomologist of the air shoots about, tumbles and twists, darts hither and thither, flits in beautiful curves, all the way from any of those known to the geometrician, to others, nearly straight in their course. Every once in a while we hear the snap of its tiny jaws as its seizes some hopelessly helpless insect, utterly lacking in any means of defence against such a well equipped and expert predatory athlete, whose movements, though apparently erratic, are, as a- matter of fact, made with the greatest possible accuracy for the attainment of their purpose.

When a June-bug, or some coleopteran of similar size, seizes his fancy as a top-off for his evening repast, what does he do but make after one in a straight course, and, as he overtakes his quarry, he so controls his movements that he is enabled to adroitly capture it in the concavity formed by the membraneous interfemoral apron stretching between his hinder pair of limbs. Instantly, upon the accomplishment of this feat, he bends forward and seizes the hapless insect with

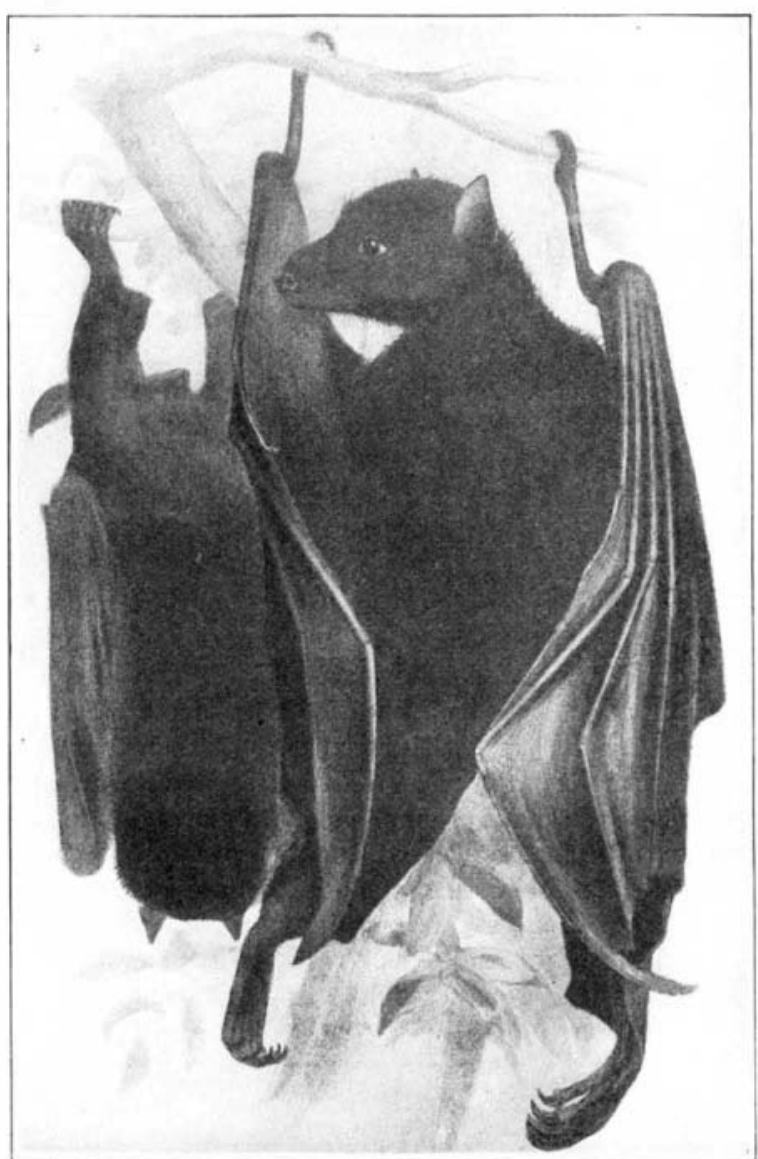

Fig. 8.-Giant fruit bat (P. grandis, male), from Solomon Islands.

Photo by the author of colored plate in P. Z. S. (PI. xxv) ; much reduced. The specimen in front is represented as hanging by its thumb, and the one behind by its feet.

his extremely sharp little teeth, and devours it as best he may.

A bat's superiority in flight is occasionally to be observed in another way; for, if one be shut up in a room, it is wonderful to note the accuracy and beauty of its flight as it flits about in all directions, in its endeavor to find some opening through which it may escape. It will alight with ease wherever it pleases; it will shoot into some small crevice to hide itself away, or suddenly dart through the slats of a windowblind and make good its escape. What is most marvelous of all, it never upsets anything, no matter how much delicate bric-a-brac may be arrayed upon the mantelshelf or elsewhere. A sparrow or any other small bird, endeavoring to flnd an exit under the same circumstances, flies around in the most insane manner possible, bumping against window-panes, knocking over small objects on the shelves, and sometimes almost braining itself against the wall or some piece of the heavier furniture in its efforts to escape.

So thoroughly has the entire anatomical structure of any one of these interesting little mammals become adapted to the requirements of its life in the air that they are, of all animals, says Flower, "the least terrestrial, not one of them being equally well fitted, as most birds and insects are, for progression on the earth. This is due to the hind as well as the fore limbs, being pressed into the service of aerial locomotion. The hind limb is so well rotated outward by the wing-membrane that, contrary to what obtains in all other vertebrates, the knee is directed backward, and corresponds in position to its serial homologue the elbow. When placed on the ground, therefore, the 
animal rests on all fours, having the knees directed upward like a grasshopper, while, in order to bring the foot into a position for forward progression, it is rotated forward and inward at the ankle. Walking under these circumstances is at best only a species of shuffle, and that this is fully recognized by the animal is evidenced by its great anxiety to take to the wing, or, if this be impossible, to ascend to some point where it can hitch itself up by the claws of the hind-legs in its usual position when at rest." (See Figs. 1 to 3 ; also "Brit. Encylo." Art. "Mammalia," vol. xv., p. 406.)

Bats of most curious form, and of a great variety of sizes and species, are found in nearly all parts of the world; while their fossil remains extend as far back as the Upper Eocene in this country and on the Continent. There can be no question but what the very remote ancestors of bats were mammals of a
strictly terrestrial type; that it is probable they subsequently became arboreal in habit, then long leapers from limb to limb, which in time demanded lateral, parachutal expansions to sustain them in such flightswhence the dermo-membranous developments between the fore and hind limb upon either side, such as is now to be observed in the case of flying-squirrels and the cobego (see descriptions beyond).

In bats and "flying-foxes," however, these skin-membranes came to be stretched between the enormously developed flngers and unduly elongated bones of the forearms, and, to some extent, the arm-bones (humeri). branes are almost completely folded up; but they are well shown in the case of the "flying-fox" in Fig. 4an animal related to the true bats, but with very different habits, as will be shown in the next article.

These last-named, most interesting mammals possess, together with the bats, true wings; their flight, as pointed out above, is more perfect than that of birds. It may be said here that they are the only true flying mammals known at the present time.

The so-called "flying" squirrels, phalangers, cobego, etc., do not fly, neither have they true wings; they simply perform a sailing flight after once springing into the air. We see the difference in such machines as a parachute (cobego) and any of the aeromotors or aeroplanes-the former, with its sustaining surface once spread, can but sail to its destination; while an aeromotor flies there and even changes its direction and destination in the air at the will of the operator.

Bats' wing-like hands, including those of the fruitbats (Pteropuso), are unique in nature at the present time. Several extinct fossil forms were similarly endowed, but they do not fall within the scope of this article to treat.

These wings of bats are extremely sensitive with respect to the sense of touch; and some species of these animals have enormous ears, and extraordinary skindevelopments about the nose and face, which are all likewise very sensitive - the whole enabling these animals to avoid things in their way and recognize objects within touch. This is important to bats; for, although their minute eyes are very keen, some of the species are actually blind. It is only the latter that merit the expression "as blind as a bat."

Some bats perform long seasonal migrations; but the majority of the northern species of both hemispheres hibernate. These habits account fully for the wide distribution of the order-some being found as far north as the Arctic Circle. However, so far no bats have been found on certain of the world's islands, as the island of St. Helena, Kerguelen Island and the Galapagos Islands.

In his very excellent work, a "List of North Amer can Land Mammals in the United States National Mu seum, 1911" (Pub. U. S. Nat. Mus. Bull. 79, 1912), Mr. Gerrit S. Miller, Jr., curator of the Division of Mammals of that institution, divides the order of bats $(\mathrm{Chi}$ roptera) in eight families, and these into seventy-one genera - the group in North America, according to this eminent authority, numbering some 216 species :Ind subspecies; these include the "leaf-nosed bats," vampires, and other large forms.

The largest and rarest of all our bats in the Northern and Middle States is the hoary bat; while the little and the large brown bat, the silver-haired bat and the red bat, among one or two

Bats generally have but one or two young at a time, and they are tiny, hairless little things when they are born; but they take at once to the hair of the mother's breasts, which are situated well up on her chest, as in the case of our species. Here they cling with great tenacity, and she, in the meanwhile, flies about as usual. It is said that she will sometimes leave her young on the limb of a tree or other convenient place, and forage about for herself for a while. When the young are older, she probably brings them food on such ccasions.

These interesting little mammals show no fear of man; on the other hand, they most frequently select places in his habitations wherein to hide during the day, and to breed, when that time arrives.

It has long been known that the "service which they render to vegetation by the destruction of insects, which in the larva state prey upon it, is very considerable, even in temperate climates. Some of the hot coun tries, in which these swarm by myriads, could not, but for them, be inhabited. In humid places, on the margins of tropical forests, mosquitos are troublesome nough as it is, but if the bats did not reduc

this article, and returning for the moment to the matter of flight among these smaller species of bats, it may be as well to record the experiments of Spallanzani, who "suspended willow rods in room in which he turned loose some bats which he had blinded; but though he frequently shifted these, so as to make the passage between them as varied and as intricate as possible, these creatures never struck against one of them, though they kept flying about in all directions." The same experim

The literature referring to these small bats of the Northern States of the United States is very extensive, and much has been written about bats of all species by naturalists all over the world for many centuries past. In some parts of England these small bats are called "flitter-mice;" in France, "bald-mice" (chauve-souris); while in Germany the people also call them "flittermice" ( fleder-möuse)

In the South Atlantic and Gulf States we meet with a small bat wherein the tail is free, that is, it is not included in the membrane stretched between the hind limbs as in other species; this species has been called the Florida free-tailed bat (Nyctinomus cynocephalus). In still other species the tail has become an instrument of prehension, and is brought into play with the hind feet when the animal suspends itself.

Passing to the larger forms of the Chiroptera, we meet with a very numerous assemblage of flying mammals that easily take a high place among the most extraordinary creatures in the world; they all possess canine teeth; enjoy the power of flight in the highest degree; are found principally in the tropics of both hemispheres, and feed on insects, small vertebrates, fruit of many kinds, while some suck the blood of other animals, which is the case of the vampires of South America, where horses are the most usual victims. Blythe says that in India the megaderms large, big-eared bat) may be heard on quiet evenings crunching the heads and bones of frogs.

The leaf-nosed bats, with the remarkable and variously formed appendages on their noses, have already been referred to on a previous page; they occur in parts of Southern Africa and in Australia, Persia, Java, and other countries. They are big bats, and of them Sir William Flower said: "From whatever point of view the Rhinolophidee may be considered, they are evidently the most highly organized of insectivorous bats. In them the osseous and cutaneous systems reach the most perfect development. Compared with theirs, the bones of the extremities and the volar membranes of other bats appear coarsely formed, and even their teeth seem less perfectly fitted to crush the hard bodies of insects. The very complicated nasal appendages, which evidently act as very delicate organs of special perception, here reach their highest development, and the differences in their form afford valuable characters in the discrimination of the snecies, which resemble one another

Then there are the "javelin bats," the "vampires," and the bats with long, extensile tongues; others wit suctorial, circular disks on certain parts of the extremities. T. tricolor from Brazil possesses these organs, an they "have the appearance of small, circular, pedunculated, hollow disks, resembling in miniature the suckin cups of cuttle-flshes, and attached to the inferior surfaces of the thumbs and soles of the feet, with which the animal is enabled to maintain its hold when creeping over smooth, vertical surfaces." (Flower.)

Turning for a moment to the "fruit bats"-some pecies of which are so large that they have been called "flying foxes"-we meet with the giants of the Order. For example, the Kalong or Malay fox bat measure no less than flve feet from tip to tip of its fully outstretched wings.

Then there is the well known, big Indian fruit or fox bat, of which Sir J. E. Tennant writes that " favorite resort of theirs near Kandy, in Ceylon, wa some india-rubber-trees, where they used to assemble in such prodigious numbers that large boughs would not infrequently give way beneath the accumulated weight of the flock;" and Pycraft speaks of another observer in Calcutta who is responsible for the statement that "they occasionally travel in vast hordes, so great as to darken the sky. Whether they are performing some preconcerted migration or bent only upon a foray to some distant feeding ground is a matter of speculation. These hordes are quite distinct from the 'long strings,' which may be seen every evening in Calcutta on their way to neighboring fruit-trees.'

Of all the extraordinary bats none is more so than the tubed-nosed fruit bat. This species presents prolongations of the nostrils into a pair of lengthy tubesstructure, the function of which science has as yet no explanation; further, it may be said that they do not occur in any other mammal outside of this group. Some of the insectivorous bats possess them, but they are very much smaller.

There are species of white bats found in Central and South America; they live, when at rest, among the silvery leaves of a species of cocoanut palm, where the total absence of color in the fur of these animals serves to conceal them, as the white fur is noticed only by chance among the leaves of this tree. On the other hand, some bats are most brilliantly colored, and among them we find Welwitsch's bat of West Africa, specimens of which were observed by the naturalists who accompanied Col. Theodore Roosevelt on his expedition into that country; these bats possess a fur of intense orange and black.

Still more remarkable are the painted bats of India, the pelage of which presents all the brilliant colors of some gorgeous moth or butterfly. Again, in the Malayan fauna, we meet with the naked bat, an interesting species that is quite lacking in any furry coat, with the exception of a ruff of hair about the neck; it has a gland at the throat that secretes a most disagreeable fluid of an oily consistence, and of a most nauseating and outrageous odor. As the young of this species cannot cling to the hair of the breast of the motheras other young of the Chiroptera do when nursingowing to her naked skin, it has come to pass that a deep sac has developed on either side of her body which form receptacles for her young.

In an 1846 edition of Darwin's "Voyage of a Naturalist" (vol. 1) in my library, I read, on page 27 , a note by that great naturalist to the effect that "The vampire bat is often the cause of much trouble, by biting the horses on their withers. The injury is generally not so much owing to the loss of blood, as to the inflammation which the presence of the saddle afterward produces. The whole circumstance has lately been doubted in England; I was therefore fortunate in being present when one (Desmodus d'orbignyi, nat.) was actually caught on a horse's back. We were bivouacking late one evening near Coquimbo, in Chile, when my servant, noticing that one of the horses was very restive, went to see what was the matter, and fancying he could see something, suddenly put his hand on the beast's withers, and secured the vampire. In the morning the spot where the bite had been inflicted was easily distinguished from being slightly swollen and bloody. The third day afterward we rode the horse without any ill effects." (Pp. 27 and 28.)

A short, but very excellent, account of these bloodsucking vampires is to be found in a work entitled: "Through Southern Mexico," by Dr. Hans Gadow (London, 1908, pp. 440-442), of which my library contains gift copy from its distinguished author.

Dr. Gadow succinctly describes the extraordinary physiological and anatomical modification in the vampires studied in Mexico by him, which so thoroughly fit them for their blood-sucking propensities. Among other things he says: "The exclusive blood diet of these creatures has brought about an absolutely unique modification of the stomach. While the oesophagus is such a narrow tube that nothing but fluid blood can pass through it, the stomach is transformed into a long, left-sided, blind sac, which is several inches in length, and coiled up upon itself." Huxley also wrote upon this subject, his paper appearing in the 1865 "Proceedngs" of the Zoölogical Society of London with a figure (pp. 386-390)

The bite of the vampire bat is like the bite of a big leech, for the blood fails to coagulate on the wound after the bat has left off sucking it; and there is reason to believe that one of the constituents of the saliva of this species of chiropteran has something to do with this fact.

As the Doctor points out, there were no horses in Mexico or Peru prior to the coming of the Spaniards to those countries and introducing them. Cattle are not attacked, for they can keep the bats off with their horns and long tails, when they possess the former 
What did these bats feed on, then, before horses and cattle came into the New World? Surely not on birds of any kind. Maybe on the deer, or perchance, on some of the other large mammals of those countries but this can be but a speculation upon the subject. In any event, the geographical range of the vampires has been greatly extended since the time of the arrival of the horses, and may be slightly extending still.

Many of the older naturalists believed that thes South American vampires preyed upon both men and cattle; Azara, for instance, stated that the inhabitants of Paraguay, although they did not fear these big, blood-sucking bats, the animals frequently entered their houses nevertheless and would suck the blood from any person they caught asleep, and were quite indifferent as to what part of the body they chose. The ill effect following the bite and bleeding was very slight, being only a mild sensation of pain for a day or so.

On the other hand, Tschudi speaks of a drunken Indian who fell asleep in the woods, and upon being bitten by a vampire, his face swelled up so that no on recognized him. Probably the alcohol had somethin to do with this, if the story be true.

It is suid that the natives sometimes use the Roussette fruit bat, one of the largest species of the Order as food, and esteem it very highly. A "Roussette" is a common name for several species of these bats in Java, where they are much dreaded on account of the havoc they play with the domesticated fruits. These they are often obliged to protect by the use of loose nets or by baskets of split bamboo.

During the day these animals hang in the trees in thousands, suspended head downwards; they appear as though they were in rows, as they are strung along on the smaller limbs, most of the host being perfectly quiet unless disturbed in some way. This attitude is well shown in Fig. 6.

As evening advances they take to flight, the arm of them repairing with unerring certainty to the native gardens, where they devour fruits of all kinds, including melons, oranges, etc.

Whether the ancient Jews were directed by their priests not to eat bats is a question; it is a well know fact that in the Bible of the Christians, this mammal is reckoned as a bird, and doubtless was so considered by the zoölogists of that work; this being the case, was not forbidden to Jews of those countries in Asi where bats occurred.

Some of the works on popular "natural history," which appeared during the middle of the last century, held forth very learnedly about what the "ancients" thought of these animals. For example, one writer remarks that though "the bats are, upon the whole, useful rather than hurtful to man, they are creatures to which poetry and superstition have in all ages had recourse to deepen the feelings of loathing and horror. They are not only of strange forms, but they are things of the doubtful light-the dim twilight-which in ages of ignorance converts white stones into ghosts and bushes into specters. They dwell in the ruined wall, or riven earth, or gloomy cavern: in eastern countries they often flnd their way into the sepulchers and catacombs of the ancients. They have been observed, therefore, as dwellers with desolation and death; and it was stretching the imagination but a little further to suppose that they were in league with those loathed and dreaded powers.

"The rapacity of the larger bats, such as are found in the warm countries, feeding during the twilight gloom, gave color to those suppositions. Hovering about the Pagan temples, they ate greedily the blood and other remains of the sacriflces. When famine or pestilence, which were then $0 i$ frequent occurrence, strewed the earth with the bodies of the dead, or when night closed upon the horrors of the battlefleld, the bats thronged to the nocturnal feast. As in all cases they came dim and apparently formless, with wing most unlike any organ bearing the same name which is spread to the light of day, they perfected their claim of poetical alliance with the infernal regions, and the powers which hold dominion over them. Hence, as the peacock was the bird sacred to Juno, the queen of Heaven, so the bat became, the creature sacred, or accursed, as may be, to Proserpine, the Empress of Hell.

"The use of bats for these purposes is as old as Homer, who very skillfully manages them in heightening the graphic effect of the splendid passage in which he describes the shrieks and wailings of the ghosts in the regions of woe; and after Homer, all poets and painters who have ventured upon similar delineations have made use of the bats for the purposes of effect. Even to this day, painters must borrow the wings of bats for their devils, in the same way that they borrow the wings of doves for their angels; and one has only to throw a deep Rembrandt shade over a piece of canvas, and show a bat's wing partly displayed from cave, in order to give an infernal air to it, with ery little painting, a good poetical representation of the gates of hell. It is easy to see how a race which is linked with such associations should have had but scanty measure of justice meted out to it by the alf-superstitious naturalists of the Middle Ages; and a remnant of the same superstition is, no doubt, the cause of much of the horror which is still con-
nected with some of the larger species of warm countries."

Although these lines were published more than half century ago, there is still to be found in the world an enormous amount of ignorance and superstition in regard to bats.

This is the first of several articles on the subject that will appear from time to time.-ED. NotE.)

\section{Comet 1915 (e) Taylor}

By E. E. Barnard

OBSERVATIONS with the large telescope were made of Taylor's comet, which has proved to be of short period. Attention has already been called $(A, J .29,138)$ to he fact that in the first part of February the comet was attended by a small companion. The origina statement that it had a double nucleus is misleading for the object was in every respect a double comet. I shall quote quite fully from my notes on these objects, for their subsequent behavior will make such note aluable for the proper interpretation of the observations made before and after the full moon in March.

At flrst the smaller (the northern) component was the fainter of the two by $1 \frac{112}{2}$ or 2 magnitudes. Both objects were fairly well deflned and were diffused toward the east into a short brush of tail. For a whil the north, or smaller, component grew fainter and the south one-the main comet-developed a small bright condensation that was almost a nucleus. The north comet then began to brighten and became quite strongly condensed. At the same time the main comet becam diffuse and fainter. It flnally entirely disappeared leaving only what at first had been the companion, which by this time was a strongly condensed comet. The position angle of the companion did not appre ciably change; that of March 22 may be in error som 10 degrees-which is not probable-on account of the extreme faintness of the original comet.

The disappearance of the main body seems to have been permanent. I have not before seen a transformation of this kind in which the original comet disappeared while the companion was still visible. During moonlight, it was not possible to tell which object was unde observation, as there was visible only one feeble condensation on the moonlit sky.

\section{SOME OTHER MULTIPLE COMETS.}

Brooks' comet, $1889 \mathrm{~V}$, it will be remembered ( $A . N$ vol. exxv., p. 177) had several companion comets, two of which remained with it for several months, and one of which at one time was brighter than the mai comet. Both, however, flnally faded out and apparently ceased entirely to exist, while the main comet was still bright. They have not been seen again, though the principal comet has returned several times.

Several other comets, Swift's of 1899 (A. J. 20, 60-61), Kopff's of 1906 ( $A . J .25,83-84)$, and Mellish's of 1915 $(A . J .29,40)$, have also had secondary or companion comets, all of which, after a more or less brief existence, disappeared. Of course the best known example of this disruption of cometary matter was Biela's comet. One of the comets of 1860 was double. Even Halley's comet showed something of this kind in May of 1910. The great comet of 1882 for a time also showed this disruptive effect. It is, therefore, not an unusual thing for a comet to develop companions, or a double condition. This breaking up of a comet would doubtless go far to account for the fact that in several cases two or more comets are found to be following nearly the same path around the Sun, and also for the entire disappearance of some of the periodic comets.

In examining the ancient records of comets, there are several cases where apparently a double or triple comet was recorded without the telescope. One of these records, which we flnd in Chambers's "Astronomy," undoubtedly refers to a comet with two companions, the three, of course, being visible to the naked eye. This was in the gear 896. The reference follows: "In this year there appeared three extraordinary stars, one larger and two smaller ones. . . They traveled together for three days. The little ones disappeared first and then the large one."

POSITION ANGLES AND DISTANCES OF THE COMPANION COMET.

The comet, as has been stated, was found to be double on February 9: The position angle and distance of the two components were measured thereafter at every opportunity. Very little change occurred in the relative position of the two, the position angle remaining about the same, and the distance slowly increasing. The comet was receding from the Earth in all the observations.

NOTES ON THE PHYSICAL APPEARANCE OF THE COMET.

1916, January 5.-It was soft and diffused like some of the periodic comets. The central brightness was 10 seconds in diameter with no deflnite nucleus.

January 8.-Tenth to eleventh magnitude. Strong condensation but no deflnite nucleus. Its general light was very soft and widely diffused. It was larger than the fleld (5 minutes)

February 2.-Small, brightly condensed to probably a small nucleus. A 14th magnitude star close south preceding, a 15th magnitude star close north following.

February 9.-The comet was double, two perfectly distinct comets whose nebulosity mingled. The south one was the brighter and had a small bright nucleus; the north one less deflnite. We will call the main omet and the companion $A$ and $B$, respectively.

February 26.-Both condensations almost stellar: about two magnitudes different in brightness. The nebulosity nearly flled the fleld and extended south following the comets. Both very little brighter pre ceding the middle. $A=12^{\mathrm{m}} . \quad B=13^{1 / 2^{\mathrm{m}}}$ or $14^{\mathrm{m}}$. The comet was faintly visible (as one) in the four-inch flnder.

February 27.-The companion seemed fainter. It was $1 / 2$ magnitudes less than the main comet.

March 4. $-A$ had lost its deflnite nucleus and was more diffused than $B$, which had almost a faint nucleus. They were both a little brighter in the middle. $B$ was $1 \frac{112}{2}$ or 2 magnitudes less than $A$. Estimated magnitudes $=12$ and $131 / 2$. Their nebulosity extended following.

March 8.-On this date the north comet $(B)$ was slightly the brighter, and had a small speck of nucleus of $14 \frac{1}{2}$ magnitude, like a small, ill-defined star. The south component $(A)$ had but little condensation and was much diffused. The two were very closely the same size. The nebulosity extended at right angles following the line between the two. There was a vague suggestion in the appearance of $A$ of a possible breaking up again

March 15.-Very faint in strong moonlight. Could not tell if it were double.

March 18.-Very faint in full moonlight. Could see only one comet:

March 22.-The north component $(B)$ observed for position. It was the brighter and was definitely condensed north preceding its center and easy to observe. The main comet $(A)$ was too faint to observe accurately for position. It was excessively difficult. The wo seemed to have interchanged individualities.

March 24.-The south component $(A)$ was not visible. What was left was simply the companion, the main comet having entirely disappeared. The greatest brightness was about $1 / 2$ minute or $3 / 4$ minute in diam eter, with possibly a faint speck of light slightly north of the center. The sky was not very transparent. March 29.-Quite strongly condensed with pernap

of the original comet. Seeing 2 , but sky poor.

April 1.-Only one comet, $131 / 2$ magnitude. A little brighter toward the middle, the nebulosity extending south following. No nucleus. It was 1 minute in diameter. Seeing good, sky good.

April 3.-Seen faintly for a moment before it was ost in clouds. Single.

April 5.-It was $131 / 2$ magnitude and $3 / 4$ minute in diameter, very gradually brighter north of the middle. Could see no trace of the original comet.

April 8.-It was single.

May 27.-The comet was 16 or $16 \frac{1}{2}$ magnitude. Very faint and diffused, but the observations are believed to be good.

A photograph was made on December 7, 1915, with the Bruce telescope. The comet was difficult to guide on with the flve-inch guiding telescope. It was estimated to be 10th or 11th magnitude. The exposure was $2^{\mathrm{h}} 50^{\mathrm{m}}$ on a good sky and shows a faint tail about $1 / 4$ degree long.

Another photograph was made on February 21, 1916 with an exposure of $1^{\mathrm{h}} 39^{\mathrm{m}}$. The scale was too small to show the comet double. Though difficult to guide on, it could be seen fairly well when the light was cut off from the wires. The sky was not very good. No other photographs were made, as the results did not seem to pay for the time spent on it.-Prof. E. E. Barnard, Yerkes Observatory, Williams Bay, Wis., in The Astronomical Journal. 